\title{
Introduction: Endovascular Neurosurgery video supplement
}

\author{
Brian Hoh, M.D., ${ }^{1}$ ANd Giuseppe LanZino, M.D. ${ }^{2}$ \\ ${ }^{1}$ University of Florida, Neurosurgery, Gainesville, Florida; and ${ }^{2}$ Mayo Clinic, Department of Neurological \\ Surgery, Rochester, Minnesota
}

It is with great pride that we present this Neurosurgical Focus video supplement on endovascular neurosurgery. We were privileged to view a multitude of outstanding quality videos demonstrating the current state-of-the-art in endovascular neurosurgery. Careful and critical review was required to narrow down the videos to a workable volume for this supplement, though there were many more that we would have liked to have included.

This issue consists of several videos that represent modern neuroendovascular techniques for the treatment of cerebrovascular disease. The videos demonstrate the cutting-edge as well as standard endovascular therapies, which will be valuable to both the novice and the expert endovascular neurosurgeons. We are greatly honored to be involved with this project, and are very proud of its content and expert authors. We confidently believe you will enjoy the video content of this supplement.

(http://thejns.org/doi/abs/10.3171/2014.V2.FOCUSIntro)

Please include this information when citing this paper: DOI: 10.3171/2014.V2.FOCUSIntro.

Address correspondence to: Giuseppe Lanzino, M.D., Mayo Clinic, Department of Neurological Surgery, Rochester Minnesota 55905. Email: Lanzino.Giuseppe@mayo.edu. 